\begin{tabular}{|c|l|}
\hline Title & Interactive combustion of two-dimensionally arranged quasi-droplet clusters under microgravity \\
\hline Author(s) & Nagata, Harunori; Kudo, Isao; Ito, Ken'ichi; Nakamura, Sosuke; Takeshita, Y asuhiro \\
\hline Citation & $\begin{array}{l}\text { Combustion and Flame, 129(4), 392-400 } \\
\text { https:/doi.org/10.1016/50010-2180/02)00353-X }\end{array}$ \\
\hline Issue Date & 2002-06 \\
\hline Doc URL & http://hdl.handle.net/2115/8535 \\
\hline Type & article (author version) \\
\hline Note & Copyright $\odot$ 2002 The Combustion Institute. \\
\hline File Information & Interactive Combustion of Quasi-droplet Clusters.pdf \\
\hline
\end{tabular}

Instructions for use 


\title{
Interactive Combustion of Two-dimensionally Arranged \\ Quasi-droplet Clusters under Microgravity
}

(Running title: Interactive Combustion of Quasi-droplet Clusters)

\author{
Harunori NAGATA ${ }^{1}$, Sosuke NAKAMURA ${ }^{2}$, Isao KUDO ${ }^{1}$, \\ Ken'ichi ITO ${ }^{1}$, Yasuhiro TAKESHITA ${ }^{3}$
}

${ }^{1}$ Department of Mechanical Science, Hokkaido University, Sapporo 060-8628, Japan.

${ }^{2}$ Graduate School of Engineering, Hokkaido University, Sapporo 060-8628, Japan.

3 Japan Space Utilization Promotion Center, Nishiwaseda, Shinjuku, Tokyo 169-8624, Japan.

The type of article: $\quad$ Full-length paper.

Address of the corresponding author:

Prof. Harunori NAGATA

Department of Mechanical Science, Hokkaido University, Sapporo 060-8628, Japan.

Tel: +81-11-706-7193 $\quad$ Fax: +81-11-706-7889

E-mail: nagata@eng.hokudai.ac.jp 


\begin{abstract}
To investigate the mutual interactions between droplets in the spray combustion, combustion of 2-dimensionally arranged quasi-droplet clusters is studied under microgravity. Quasi-droplet samples, which are solid in room temperature and change into liquid just after the ignition, consist of alcohol (propanol, butanol, pentanol, or hexanol) and polyethylene glycol with a volumetric ratio of 2:1. Seven samples sustained by glass rods form a 2-dimensional quasi-droplet cluster. Electrically heated nichrome wires ignite all samples in the cluster simultaneously. Single envelope flames that surround the clusters appeared. The results show that the sample spacing has a strong effect on the shape and movement of the flame. Sample clusters with large sample spacings come to the external group combustion through the scavenging combustion mode, whereas the small spacing clusters start directly with the external group combustion. At large sample spacings, the distance from the edge of the sample cluster to the flame (flame distance) increases to a maximum value and then decreases with time. The period of flame growth is prolonged with decreasing sample spacing and finally, at a small enough sample spacing, the flame distance keeps increasing until the flame disappears. This flame movement is attributed to the fuel vapor accumulation effect, which becomes more dominant with decreasing sample spacing. The burning lifetime decreases monotonically and approaches the value of the single flame with increasing sample spacing. The flame distance decreases monotonically and approaches the single flame radius with increasing sample spacing also. These results render important confirmations of the external group combustion phenomena and prove the importance of the two kinds of unsteadiness, i.e., the scavenging combustion with large droplet interval and the fuel vapor accumulation effect with small droplet interval, in group combustion.
\end{abstract}




\section{INTRODUCTION}

In spray combustion, fuel droplets burn in droplet clouds and their combustion mechanism is different from that of a single droplet because of mutual interactions. To investigate the basic mechanisms of these interactions, the combustion of two droplets and droplet arrays has been studied experimentally [1-3] and theoretically [4-7]. Although these simple arrangements are effective to improve basic understanding from a microscopic viewpoint, a large gap exists between spray combustion and the understanding obtained by these arrangements. Observing a well-characterized two or three dimensional burning droplet cluster is desirable to fill this large gap.

For single droplet combustion, there are many studies concerning unsteady state droplet combustion. The interest in unsteady phenomena arose from experimental observations that the ratio of flame-to-droplet diameter keeps increasing during single droplet combustion [8]. This observation is inconsistent with the quasi-steady theory, which states that the ratio of the flame-to-droplet diameter is constant [9]. Subsequent studies have clarified that the main factors causing this contradiction are gas-phase diffusive unsteadiness [10], droplet heating [11], and fuel vapor accumulation effect [12]. For multiple droplet systems, few investigations concerning unsteady droplet combustion have been made. Comparing with the considerable data accumulated on the unsteady process of single droplet burning, experimental data on multiple droplet systems are limited. Theoretically, Chiu et al. have predicted other unsteadiness specific to multiple droplet systems [13]. They had made quasi-steady analysis about the collective interaction of the droplet-gas phase in a spray and predicted the group combustion phenomena $[14,15]$. Following the quasi-steady analysis, they numerically predicted the unsteady process of group combustion: The combustion sequence for multiple droplet systems starting from the initially unburned state consists of preheating, 
mixing, ignition, scavenging combustion, and quasi-steady group combustion. The scavenging combustion continues until all the air captured in the droplet cloud is consumed. In diluted cluster cases, the scavenging combustion can occupy a large fraction of the total combustion time. In dense cluster cases, the unsteady behavior can dominate the total combustion time because of the fuel vapor accumulation effect. When the initial fuel vapor concentration around the droplet cloud is low, immediately after ignition most of the fuel vaporized is stored around the droplet cloud rather than being consumed at the flame [12]. The group combustion theory shows that the distance from the droplet cloud to the envelope flame increases with decreasing droplet spacing. This means that the amount of fuel vapor present in the envelope flame becomes more significant when compared with the droplets mass with decreasing the droplet interval. Therefore, the importance of fuel vapor accumulation increases with decreasing droplet spacing. Accordingly, unsteadiness arises as a dominant factor in group combustion with both large and small droplet spacings. To accumulate knowledge about these unsteady processes, proper experimental studies accompanying theoretical approaches are necessary.

A promising method to simulate group combustion is to fix in space spherical fuel samples that are large enough to afford easy arrangement and observation. When the fuel sample's size is large, however, the effect of natural convection increases, resulting in the modification of the combustion field. In the present study, combustion of quasi-droplet samples arranged 2-dimensionally is observed under microgravity to eliminate natural convection. The long duration microgravity (10 seconds) is produced by the 500-m drop shaft of Japan Microgravity Center (JAMIC). Four kinds of alcohols (propanol, butanol, pentanol, and hexanol) are employed as the fuels and they are mixed into polyethylene glycol (PEG) to make them solid state at room temperature. This treatment enables experimenters easy set-up with respect to initial sample diameter and 
sample arrangement. The effects of sample spacing on flame shape, flame shape history, and flame lifetime are investigated to examine the combustion behavior of multiple droplet systems.

\section{EXPERIMENTAL APPARATUS AND METHOD}

\section{Experimental apparatus}

The experimental apparatus consists of a combustion chamber, an 8-mm VTR camera, a 35-mm single-lens reflex camera, controlling system, and battery units. The combustion chamber is made of acrylic plate and is $365 \mathrm{~mm}$ (W) x $367 \mathrm{~mm}$ (D) x 408 mm $(\mathrm{H})$. To protect the acrylic plates against fire, tin plates and heat-resistant black paint cover all acrylic plates except for an observing window. Figure 1 shows the detail of the combustion chamber. Electrically heated nichrome wires ignite the fuel samples. To ignite all samples simultaneously, the nichrome wires form a flat face that covers all the fuel samples. Immediately after ignition, the nichrome wires move away from the fuel samples.

\section{Samples}

Fuels employed in this study are 1-propanol (CH3(CH2)2OH), 1-butanol (CH3(CH2)3OH), 1-pentanol (CH3(CH2)4OH), and 1-hexanol (CH3(CH2)5OH). One of these alcohols is mixed into PEG (HOCH2(CH2OCH2)xCH2OH) to make them solid state at room temperature. This treatment enables experimenters easy control of the initial sample diameter and arrangement. PEG is an ether with a molecular weight less than 100,000 . It is familiar as an ointment and a suppository. The mean molecular weight and melting point of the PEG in this study are 6,000 to 7,000 and 333 to $336 \mathrm{~K}$, respectively. It is a white powder at room temperature. Because PEG is a liquid at the 
boiling point of all of the alcohols employed in this study, the samples burn in the liquid phase. PEG does not contribute as a fuel because the vapor pressure of PEG is negligibly small at the boiling point of the alcohols. The procedure to prepare the sample is;

(1) Melt the PEG powder by warming it in hot water.

(2) Mix the PEG and an alcohol fuel with the volumetric ratio of about 1:2.

(3) Soak a glass rod in the mixture and congeal the droplet in room temperature.

(4) Repeat the above procedure until the sample grows to the prescribed size (about 2.5 $\mathrm{mm}$ in diameter).

As Fig. 1 shows, the seven samples form a hexagon. The diameter of each grass rod is less than $0.5 \mathrm{~mm}$. They have almost the same length, with errors less than $0.5 \mathrm{~mm}$, to arrange samples in the same plane. The interval of each samples are defined as the sample spacing L.

\section{RESULTS AND DISCUSSION}

Flame shape

Figure 2 shows consecutive flame photographs after ignition with sample spacings of $4 \mathrm{~mm}$ (the left column) and $30 \mathrm{~mm}$ (the right column). The time sequence is from top to bottom. Hexanol is the fuel. In the present study, most of all flames are dim blue flames that are hard to see. To take clear photographs of these dim blue flames the authors employed high-speed films (GX3200, Konica) and set the shutter speed of the $35 \mathrm{~mm}$ camera to 0.5 second. Although the 2-dimentional arrangement can impede the oxygen access only in the droplet plane, a clear differentiation still exists between internal scavenging combustion and external group combustion; one can distinguish them by simply seeing if there is a flame front between fuel samples. These two series of figures 
clearly show interesting trends depending on the sample spacing: When the sample spacing is $30 \mathrm{~mm}$, each sample starts with individual flames surrounding each droplet. As the air is consumed by the initial scavenging combustion, the flames grow until they flames merge with each other into a single flame that surrounds the sample cluster. Oxidizer from the cluster exterior supports this six-leaf envelope flame. The combustion ends with the external group combustion. When the sample spacing is $4 \mathrm{~mm}$, a single envelope flame encloses the sample cluster throughout the process. Accordingly, the sample cluster starts directly with external group combustion. One can see that the envelope flame size increases up to $t=2.25 \mathrm{~s}$ here. As described later, the flame size keeps increasing until it disappears. The dependence on sample spacing described above is common to all the fuels employed in this study.

Figure 3 shows the effect of sample spacing on the flame shape. The fuels in the left and right columns are butanol and hexanol, respectively. Each photograph shows the moment when the flame size reaches a maximum. These figures show a clear trend from external group combustion to single droplet combustion with an increase in sample spacing. Note that the envelope flame approaches the edge of the sample cluster with increasing sample spacing. According to group combustion theory, the envelope flame approaches the edge of the droplet cloud as the droplet spacing increases. Consequently, the behavior of the envelope flame in this study renders a confirmation of the group combustion phenomena.

\section{Flame distance}

The sample spacing greatly affects flame movement. Figures 4 to 6 show temporal variations of flame distance. The fuels are butanol, pentanol, and hexanol. The flame distance is the distance from the edge of the sample cluster to the flame. It is calculated as (the flame diameter $-2 \mathrm{~L}$ )/2, where $\mathrm{L}$ is the sample spacing. The diameter of the 
envelope flame is the average of three measurements along three axes, one passing through the center of the cluster. Judging from the shutter speed of 0.5 second and flame propagation velocities of approximately $1 \mathrm{~mm} / \mathrm{s}$, the error due to the long exposure time is less than $1 \mathrm{~mm}$. In Fig. 8, the data with a sample spacing of infinity means the flame radius of as single droplet. It was commonly observed for all three fuels that each sample starts with single droplet combustion when the sample spacing is $30 \mathrm{~mm}$. It starts with an envelope flame surrounding the sample cluster for all other sample spacings. Note that the maximum flame distance increases with decreasing sample spacing in all fuels. This is an important example of the group combustion phenomena. Another important point is that the flame distance continuously increases with time for small sample spacings. With the single sample in Fig. 6 (with sample spacing of infinity), the flame diameter increases to a maximum value and then decreases. This is typical flame behavior in single droplet combustion [8]. The main causes of the initial flame growth are the heating of the droplet [11] and the accumulation of fuel vapor around the droplet [12]. For all fuels, the period of flame growth increases with decreasing sample spacing and finally, with a sample spacing of $4 \mathrm{~mm}$, the flame distance keeps increasing until the flame disappears. There is no doubt that the cause of this flame movement is the mutual interaction of droplets. The initial flame radius of the single droplet in Fig. 6 is distinctly larger than the other initial flame distances of sample clusters. This difference may be attributed to the fact that the same ignition sequence was used in both the single droplet and droplet cluster cases.

Generally, the fuel evaporation rate strongly affects the flame standoff point or flame distance. Because the rate controlling step of the vaporization is the heat transfer to the droplet, a fuel droplet of smaller latent heat of evaporation per unit mass has a larger evaporation rate. For three alcohols mentioned in Figs. 4 to 6, 1-buthanol, 1-pentanol, and 1-hexanol are in the order of decreasing latent heat of evaporation per unit mass. 
This means that the fuel evaporation rate should increase in this order because the heat of combustion and thermo-physical properties between the droplet and flame are not significantly different. Although Figs. 4 to 6 show that the flames with larger fuel evaporation rates tend to obtain larger flame distances, the effect of sample spacing on flame movement is qualitatively similar for all fuels. All fuel droplets in this study contain PEG with initial volumetric ratio of $1 / 3$ to make them solid state at room temperature. Although the saturated vapor pressure of PEG at the boiling points of the fuels is virtually zero, PEG can reduce the fuel's evaporation rate by reducing the fuel mass fraction at the droplet surface. Unfortunately, due to a lack of droplet size history data, it is not clear how much PEG reduced the fuel's evaporation rate. However, the effect of sample spacing on flame movement is common qualitatively even if the evaporation rate changes as mentioned previously. Accordingly, the change in flame movement due to the mutual interaction of the droplets in Figs. 4 to 6 is consistent with pure alcohol fuel droplets.

According to the group combustion theory, the flame distance decreases with decreasing group combustion number, $G$. Because $G$ decreases with decreasing mean droplet diameter in the cluster, the flame distance should decrease with time. The experimental results with the small sample spacings are inconsistent with this prediction. Figure 7 describes the reason the flame distance continuously increases with small sample spacing. The horizontal and vertical axes are $G$, increasing to the left, and the flame distance, respectively. The broken line stands for the quasi-steady flame distance $R_{f}(G)$, which increases with increasing $G$. Continuous lines show experimental $G$ (flame distance) trajectories. After ignition, $G$ starts decreasing from the initial group combustion number, $G_{0}$, because of the decreasing mean droplet diameter. Immediately after ignition most of the fuel vaporized is stored around the cluster rather than being consumed at the flame. Due to the insufficient fuel supplied, the flame lies close to the 
cluster. As the fuel vapor concentration increases, more fuel vapor can contribute to combustion and the flame subsequently propagates outward. Near burnout, the instantaneous amount of fuel burned exceeds the amount vaporized because of the decreased droplet size and the extended fuel vapor region. Consequently, the actual $G$ (flame distance) trajectory with small $G_{0}$ goes to the upper right direction initially, approaches and passes over the broken line representing quasi-steady combustion, and then turns to the lower right direction. Because the initial group combustion number $G_{0}$ increases with decreasing sample spacing, the $G$ - (flame distance) trajectory moves to the left direction as Fig. 7 describes. To attain quasi-steady combustion, the cluster needs to accumulate more fuel vapor with increasing $G_{0}$. This means that the amount of fuel vapor needed becomes more significant comparing with the droplets mass with increasing $G_{0}$. As the result, with small droplet intervals, (i.e., with large $G_{0}$,) the envelope flame cannot reach quasi-steady combustion and continuously increases in size until it disappears.

Figure 8 shows the burning lifetime as a function of sample spacing. Open circles and open triangles are results with butanol and hexanol, respectively. The vertical axis is the number of $35 \mathrm{~mm}$ still camera frames that records the flame. Because the shooting interval is 0.75 second, the number of frames, $n$, is between $0.75(n-1)$ and $0.75(n+1)$ second. With both fuels, the flame lifetime increases as sample spacing decreases. Note that in the hexanol case, the burning lifetime approaches that of the single sample with increasing sample spacing. The increase in flame lifetime caused by the mutual interaction of droplets suggests that the heat transfer rate from the flame to the fuel samples decreases with the decreasing sample spacing. The decrease in the heat transfer rate is due to the increase in the flame distance $[14,15]$.

Figure 9 shows the maximum flame distance during a test as a function of sample spacing. In many cases, as Figs. 4 to 6 show, the maximum flame distance appears just 
before extinction. Propanol, butanol, pentanol, and hexanol are in the order of increasing maximum flame distance. This order agrees with the order of decreasing latent heat of evaporation per unit mass. Except for propanol, with which only one data is obtained, a decrease in sample spacing causes increase in the of maximum flame distance. Again, this result renders an important confirmation of the external group combustion phenomena. The envelope flame approaches the droplet cluster with increasing droplet spacing.

Figure 10 shows the dependencies of the non-dimensional flame distance on the non-dimensional sample spacing. The flame distance and sample spacing are divided by the flame radius obtained by quasi-steady theory [16] and the initial diameter of the sample, respectively. Assuming burning quasi-steady, the flame radius is;

$$
B_{o, q}=\frac{\Delta h_{c} / k+C_{p, g}\left(T_{\infty}-T_{s}\right)}{q_{i-l}+h_{f g}}, \quad \frac{r_{f}}{r_{s}}=\frac{\ln \left(1+B_{o, q}\right)}{\ln [(1+k) / k]}
$$

where $r_{f}, r_{s}, k, h_{c}, C_{p, g}, T_{\infty}, T_{s}, q_{i-l}$, and $h_{f g}$ are flame-radius, the radius of the droplet, stoichiometric mass ratio, heat of combustion per unit mass of fuel, specific heat at constant pressure, ambient temperature, droplet surface temperature, energy required to heat up the droplet surface, and heat of vaporization, respectively. Using the non-dimensional flame distance shows the effect of sample spacing on the flame distance comprehensively, covering all of the fuels employed in this study. The flame distances should be non-dimensionalized by the radius of a single flame, but it is not possible because of a lack of data on the single flame except for the hexanol case. Using the theoretical flame radius is the next best idea. Although the above equation is known to greatly overpredict the flame radius and does not include the effect of PEG addition, the non-dimensional flame distances of butanol, pentanol, and hexanol at a non-dimensional sample spacing of 11 to 12 practically coincide with each other, 
showing that comprehensive discussion is possible. This is because the difference in flame size for these fuels is caused by differences in the latent heat of evaporation per unit mass, which is correctly accounted for by the equation. The figure clearly shows that the flame distance decreases monotonically and approaches the single flame radius with increasing sample spacing.

\section{CONCLUSION}

To investigate the mutual interaction between droplets in spray combustion, combustion of 2-dimensionaly arranged quasi-droplet clusters is studied under microgravity. A single envelope flame that surrounds the sample cluster appeared. The results show that sample spacing has a strong effect on the shape and movement of the flame. Sample clusters with large sample spacing come to the external group combustion mode through the scavenging combustion mode, whereas the small spacing clusters start directly with the external group combustion mode. At large sample spacings, the flame distance increases to a maximum value and then decreases with time. The period of flame growth is prolonged as the sample spacing decreases and finally, at small sample spacings, the flame distance increasing until the flame disappears. This flame movement is attributed to the fuel vapor accumulation effect, which becomes more dominant with decreasing sample spacing. The burning lifetime decreases monotonically and approaches the value of the single flame with increasing sample spacing. The maximum flame distance decreases monotonically and approaches the single flame radius with increasing sample spacing. These results render important confirmations of the external group combustion phenomena and prove the importance of the two kinds of unsteadiness, i.e., the scavenging combustion at large droplet spacings and the fuel vapor accumulation effect at small droplet spacing. 


\section{Acknowledgment}

This work was performed under the management of the Japan Space Utilization Promotion Center (JSUP) as a part of the R\&D project of the 'Advanced Combustion Science Utilizing Microgravity' supported by the New Energy and Industrial Technology Development Organization (NEDO).

\section{References}

[1] Miyasaka, K. and Law, C. K., Proc. Combust. Inst. 18: 283-292 (1981).

[2] Xiong, T. Y. et al., Proc. Combust. Inst. 20: 1781-1787 (1985).

[3] Mikami, M. et al., Proc. Combust. Inst. 25: 431-437 (1995).

[4] Brzustowski, T. A. et al., AIAA Journal 17: 1234-1242 (1979).

[5] Labowsky, M., Combust. Sci. Technol. 22: 217-226 (1980).

[6] Umemura, A. et al., Combust. Flame 41: 45-55 (1981).

[7] Umemura, A., Proc. Combust. Inst. 18: 1355-1363 (1981).

[8] Kumagai, S. et al., Proc. Combust. Inst. 13: 778-785 (1971).

[9] Godsave, G. A. E., Proc. Combust. Inst. 4: 818-830 (1953).

[10]Waldman, C. H., Proc. Combust. Inst. 15: 429-442 (1971).

[11] Law, C. K. and Sirignano, W. A., Combust. Flame 28: 175-186 (1977).

[12]Law, C. K. et al., Combust. Flame 38: 173-198 (1980).

[13]Chiu, H. H. and Lin, C. L., Proc. Combust. Inst. 26: 1653-1661 (1997).

[14]Chiu, H. H. and Liu, T. M., Combust. Sci. Technol. 17: 127-142 (1977).

[15]Chiu, H. H. et al., Proc. Combust. Inst. 19: 971-980 (1982).

[16] Turns, S. R., An Introduction to Combustion, McGRAW-HILL, 1996, p. 327. 
List of figure captions

Fig. 1 Detail of the combustion chamber.

Fig. 2 Consecutive flame photographs after ignition.

Fig. 3 The effect of sample spacing on the flame shape.

Fig. 4 Histories of the flame distance (Butanol).

Fig. 5 Histories of the flame distance (Pentanol).

Fig. 6 Histories of the flame distance (Hexanol).

Fig. 7 Effect of sample spacing on G - (flame distance) trajectory.

Fig. 8 Burning life time as a function of sample spacing.

Fig. 9 The maximum flame distance as a function of sample spacing.

Fig. 10 (The Maximum flame distance) $/ \mathrm{r}_{\mathrm{f}}$ as a function of (Sample spacing) $/ \mathrm{r}_{\mathrm{s}}$. 


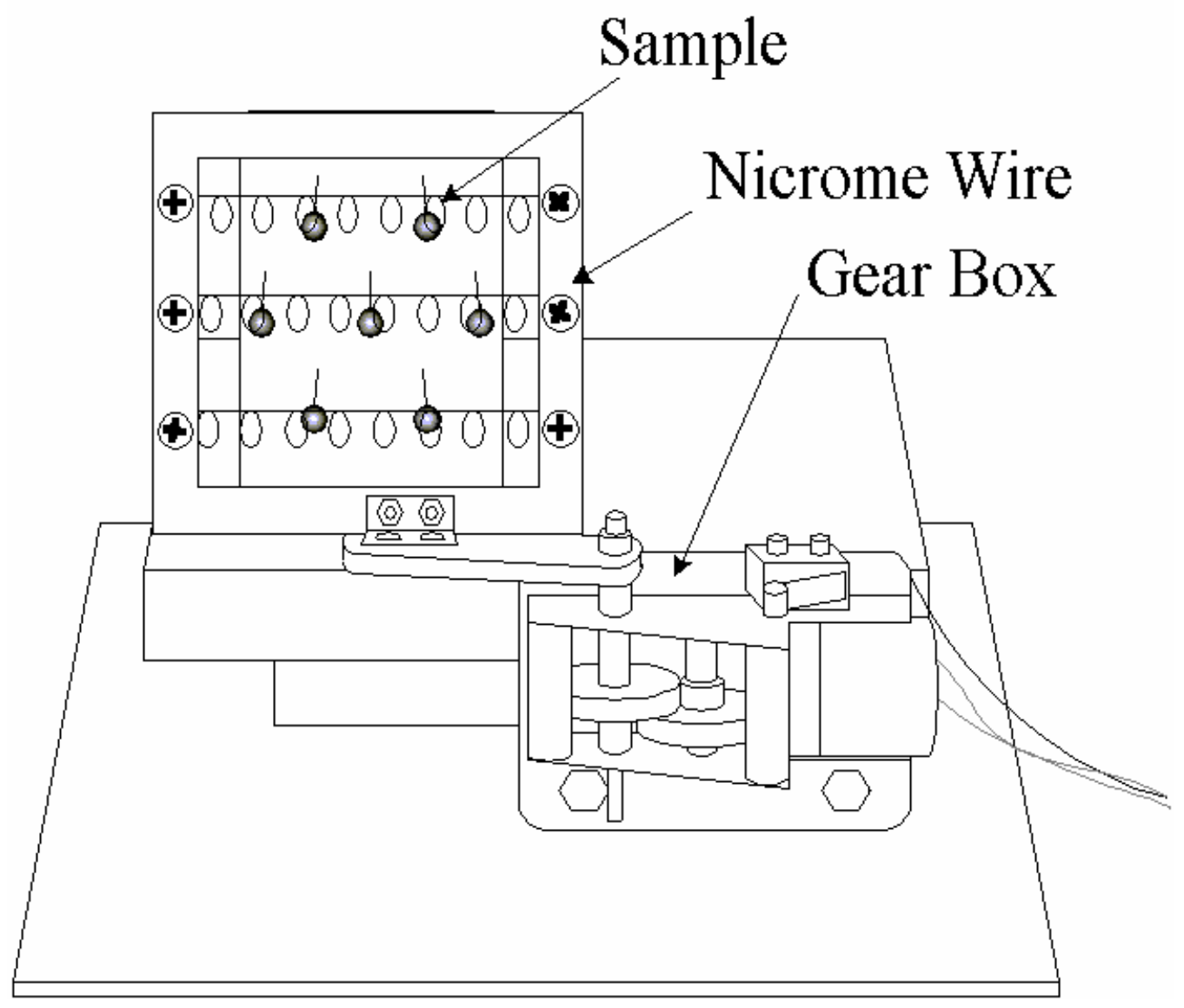

Fig. 1 Detail of the combustion chamber.

Harunori NAGATA, Sosuke NAKAMURA, Isao KUDO, Ken'ichi ITO, Yasuhiro TAKESHITA 


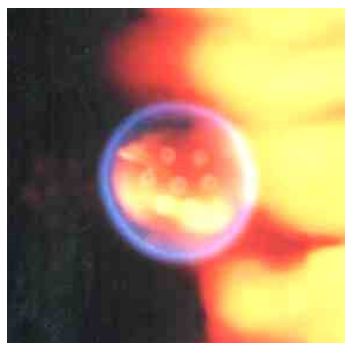

$+0 \mathrm{sec}$

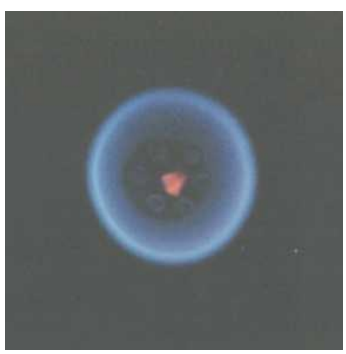

$+0.75 \mathrm{sec}$

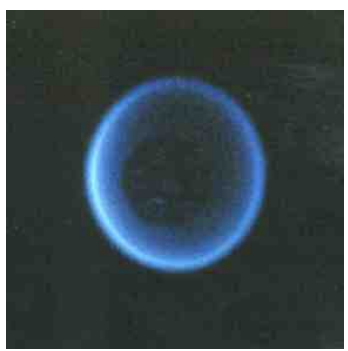

$+1.5 \mathrm{sec}$

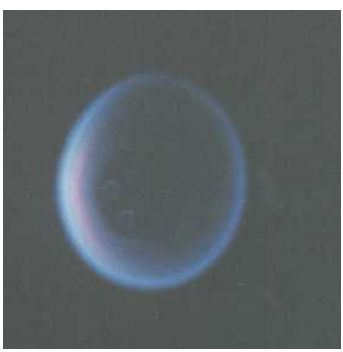

$+2.25 \mathrm{sec}$

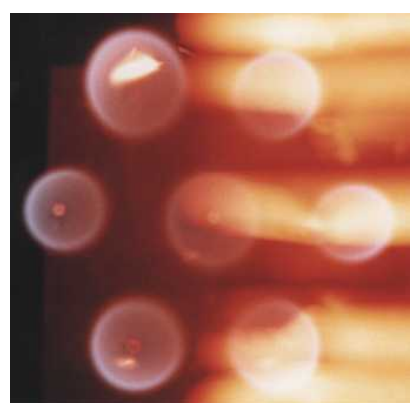

$+0 \mathrm{sec}$

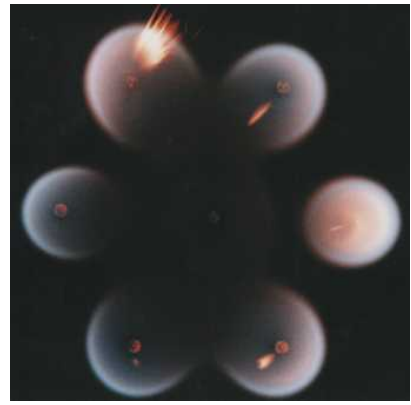

$+0.75 \mathrm{sec}$

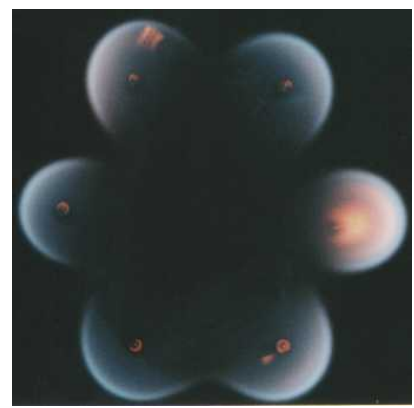

$+1.5 \mathrm{sec}$

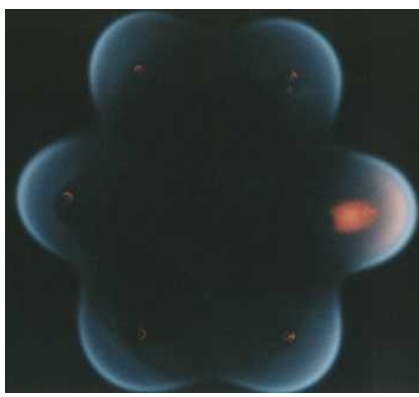

$+2.25 \mathrm{sec}$

(B) $\mathrm{L}=30 \mathrm{~mm}$

(A) $\mathrm{L}=4 \mathrm{~mm}$

Fig. 2 Consecutive flame photographs after ignition.

Harunori NAGATA, Sosuke NAKAMURA, Isao KUDO, Ken'ichi ITO, Yasuhiro TAKESHITA 


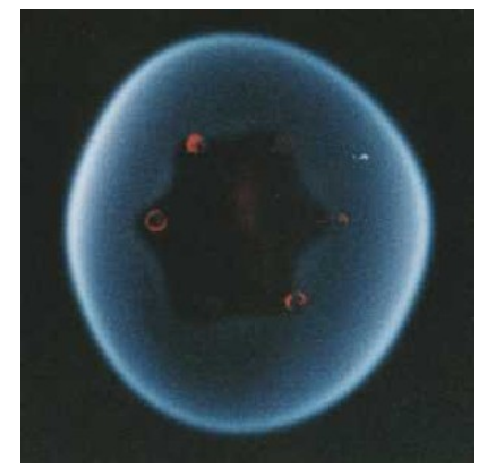

$\mathrm{L}=10 \mathrm{~mm}$

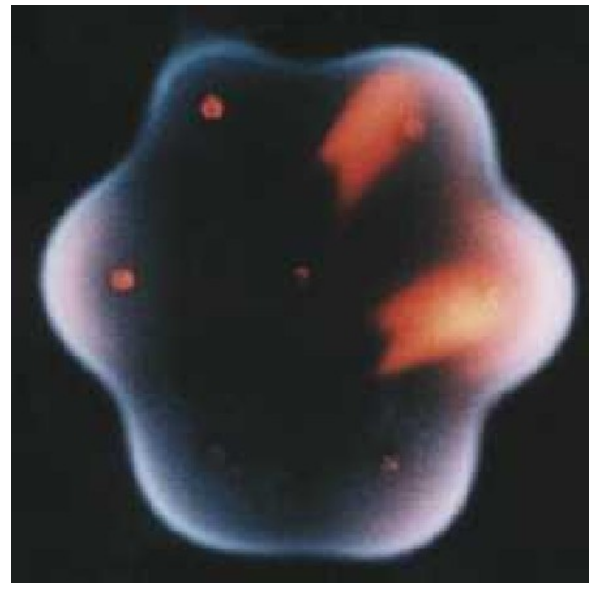

$\mathrm{L}=20 \mathrm{~mm}$

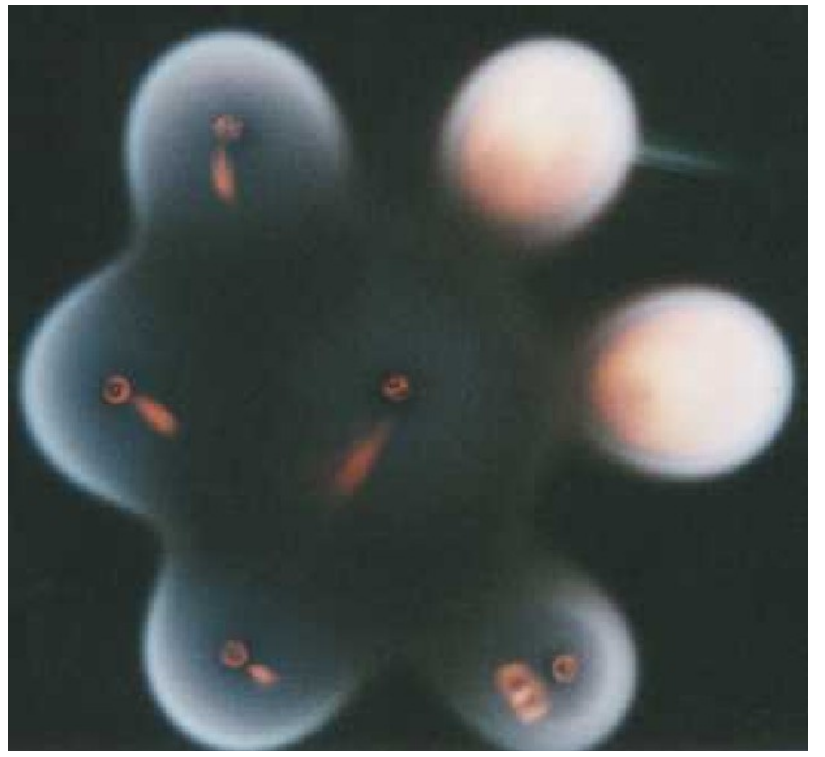

$\mathrm{L}=30 \mathrm{~mm}$

(A) Butanol

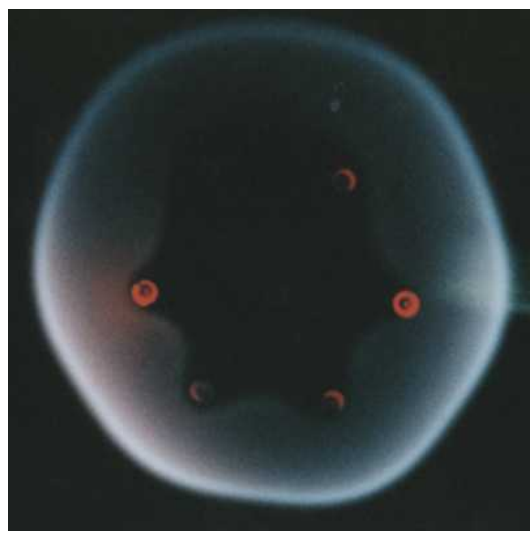

$\mathrm{L}=14 \mathrm{~mm}$

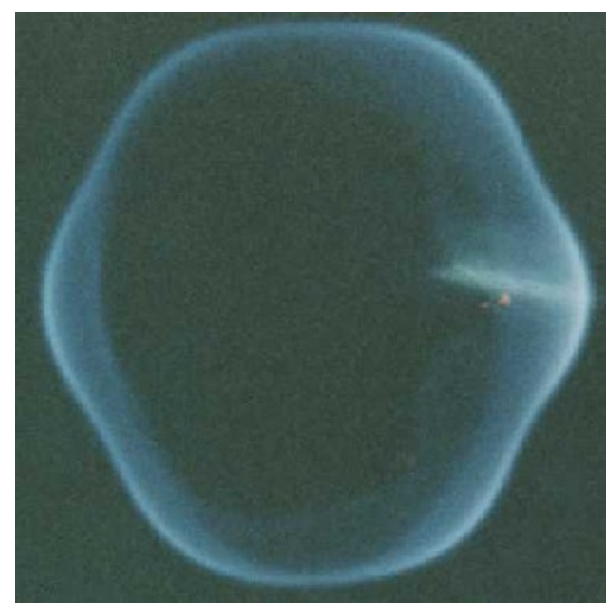

$\mathrm{L}=20 \mathrm{~mm}$

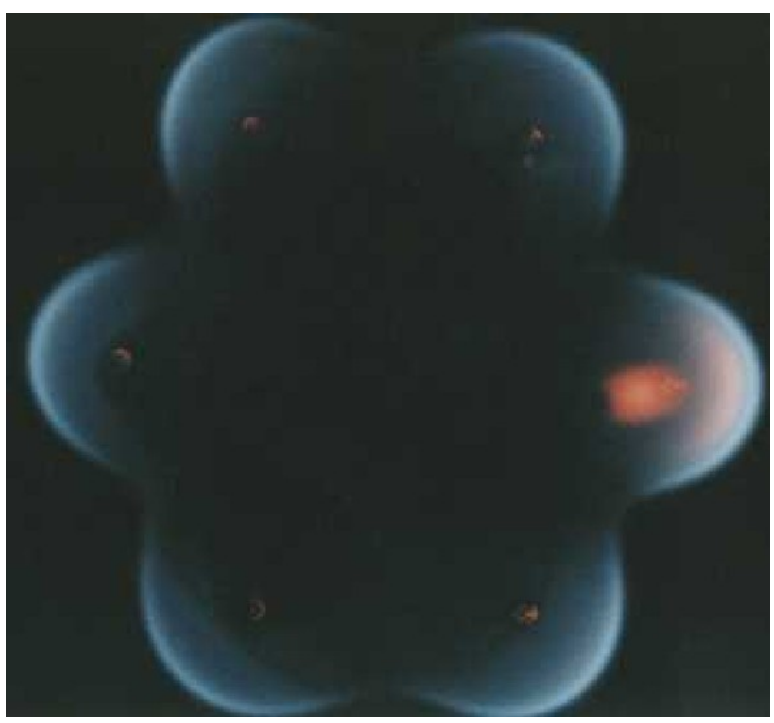

$\mathrm{L}=30 \mathrm{~mm}$

(B) Hexanol

Fig. 3 The effect of sample spacing on the flame shape.

Harunori NAGATA, Sosuke NAKAMURA, Isao KUDO, Ken'ichi ITO, Yasuhiro TAKESHITA 


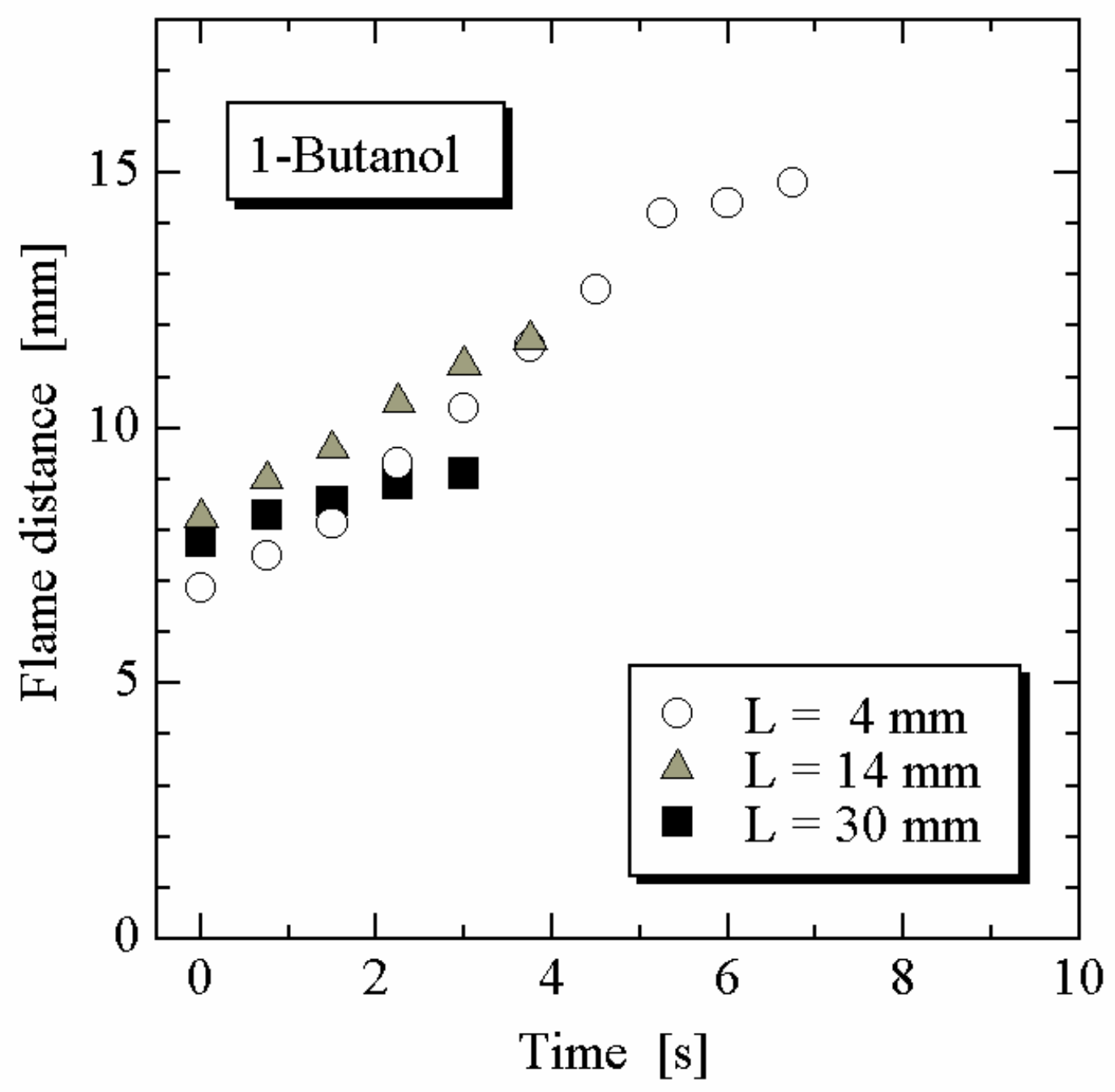

Fig. 4 Histories of the flame distance (Butanol).

Harunori NAGATA, Sosuke NAKAMURA, Isao KUDO, Ken'ichi ITO, Yasuhiro TAKESHITA 


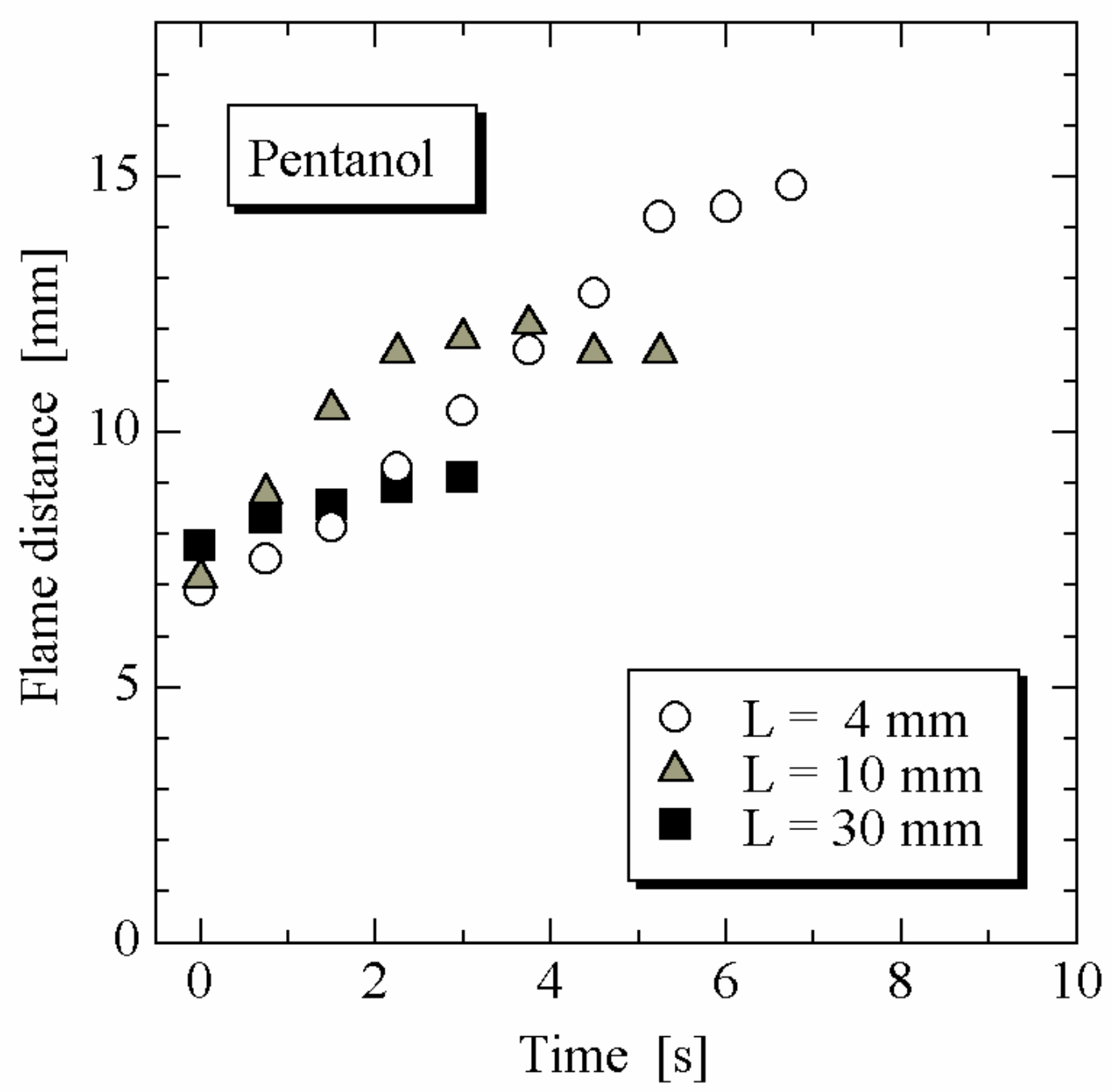

Fig. 5 Histories of the flame distance (Pentanol).

Harunori NAGATA, Sosuke NAKAMURA, Isao KUDO, Ken'ichi ITO, Yasuhiro TAKESHITA 


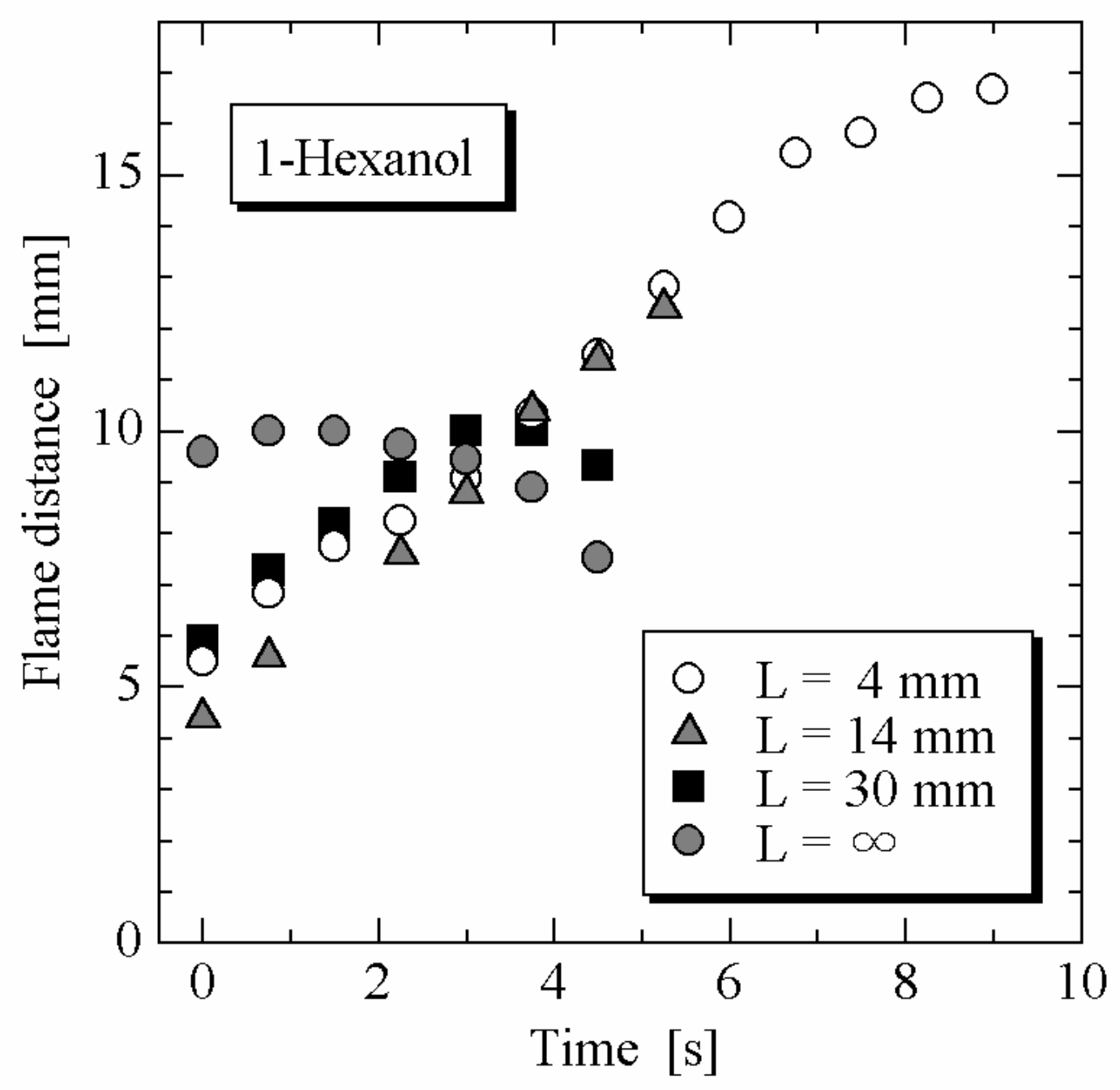

Fig. 6 Histories of the flame distance (Hexanol). Harunori NAGATA, Sosuke NAKAMURA, Isao KUDO, Ken'ichi ITO, Yasuhiro TAKESHITA 


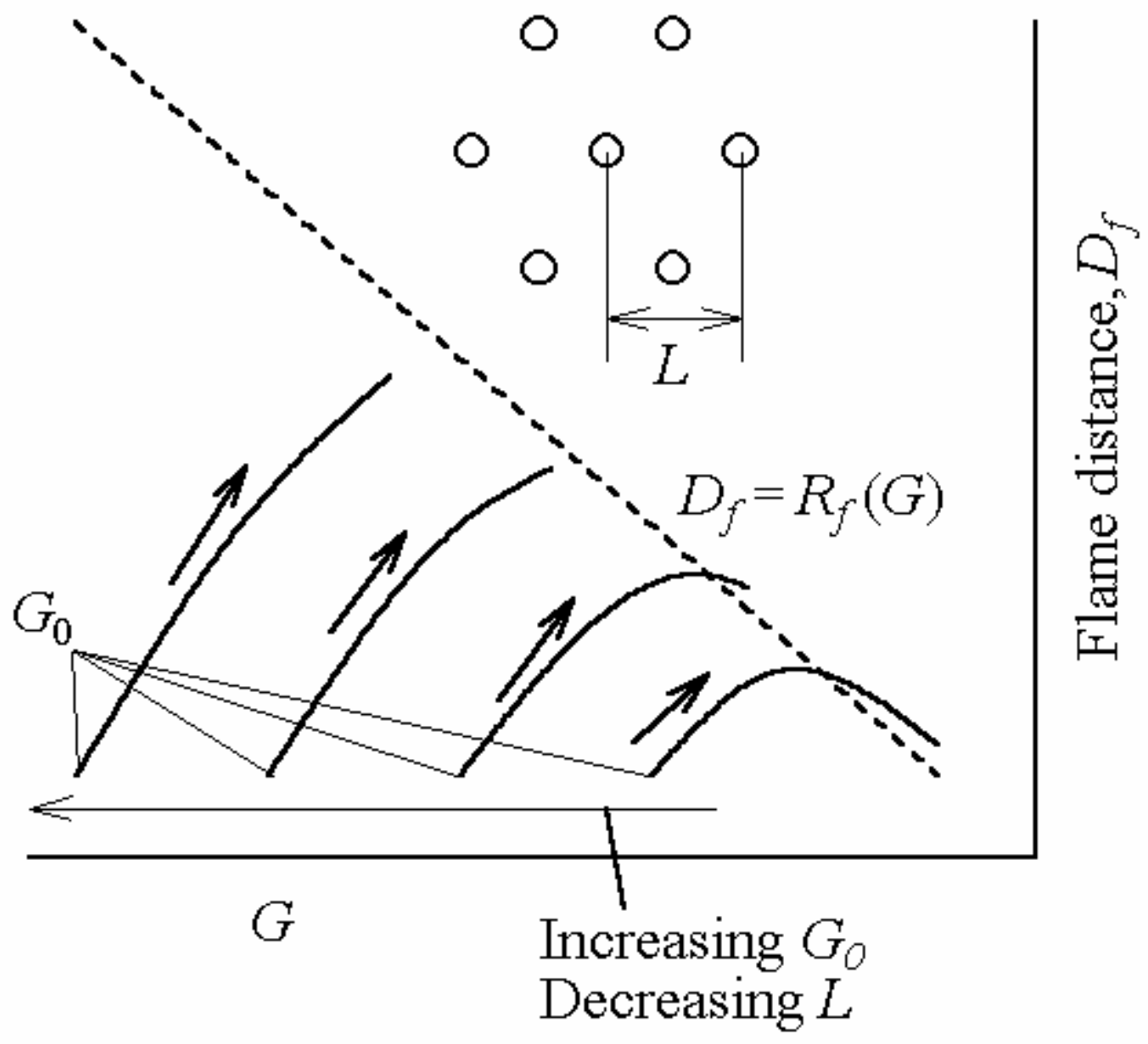

Fig. 7 Effect of sample spacing on G - (flame distance) trajectory.

Harunori NAGATA, Sosuke NAKAMURA, Isao KUDO, Ken'ichi ITO, Yasuhiro TAKESHITA 


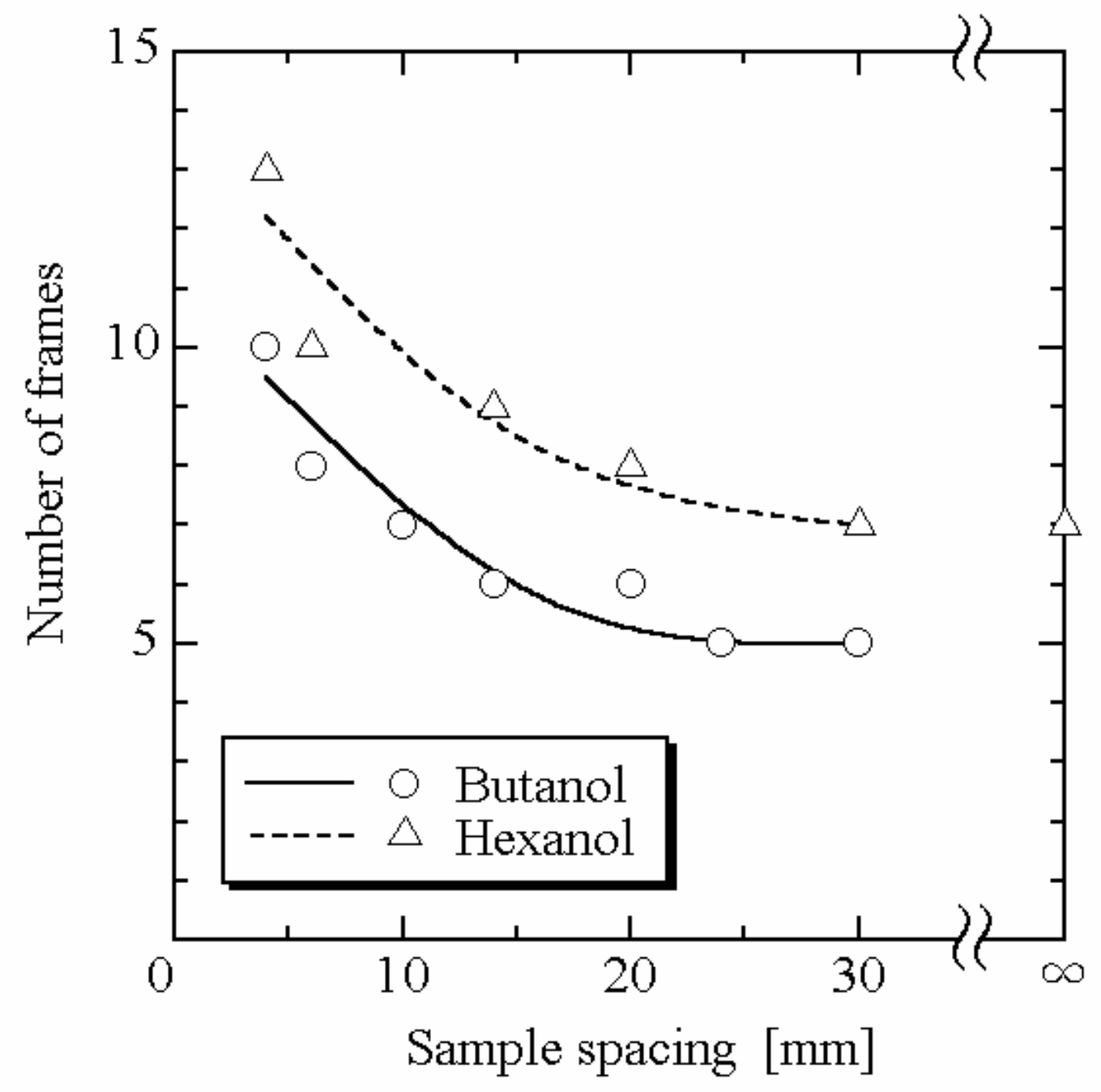

Fig. 8 Burning life time as a function of sample spacing.

Harunori NAGATA, Sosuke NAKAMURA, Isao KUDO, Ken'ichi ITO, Yasuhiro TAKESHITA 


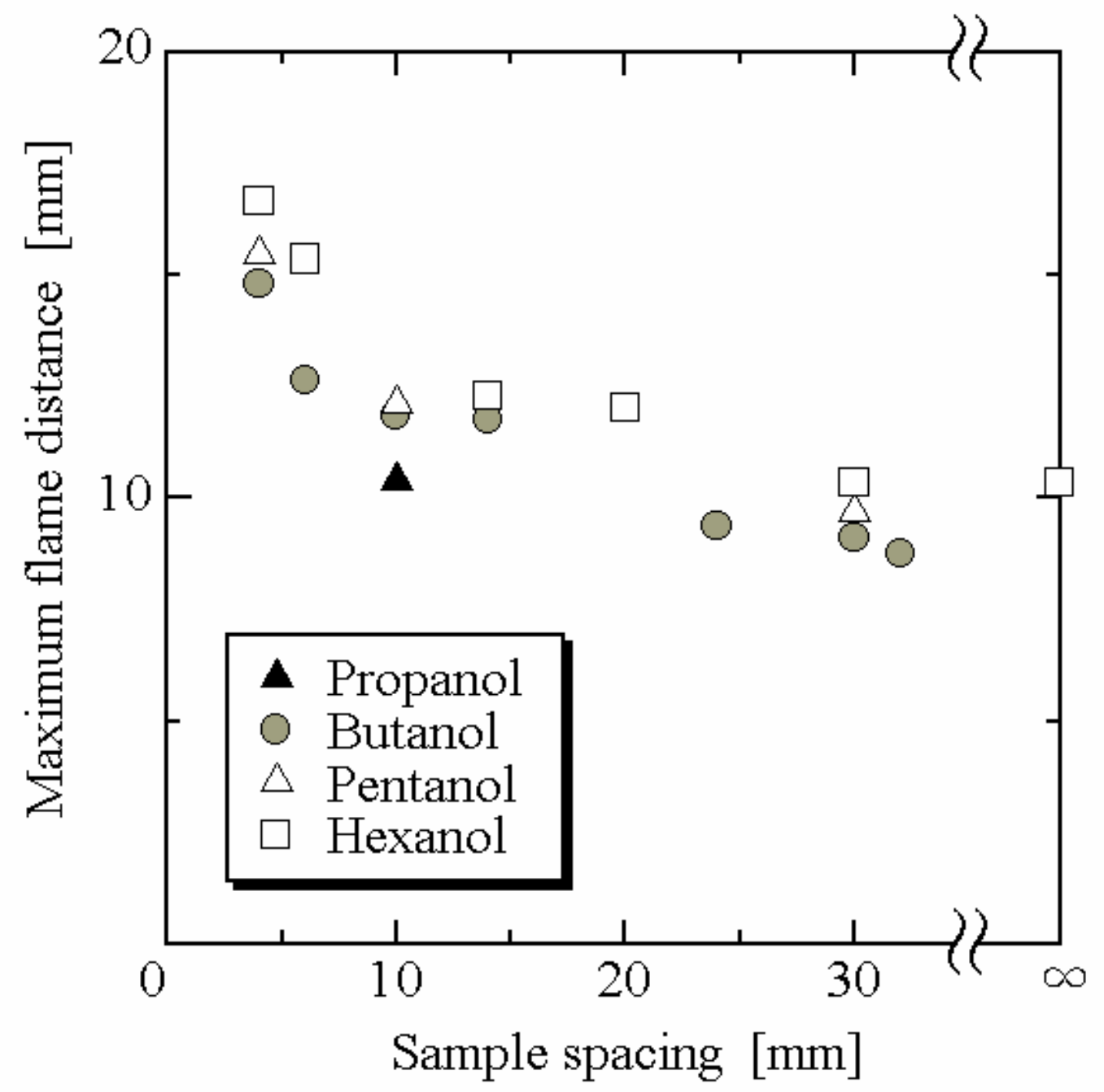

Fig. 9 The maximum flame distance as a function of sample spacing.

Harunori NAGATA, Sosuke NAKAMURA, Isao KUDO, Ken'ichi ITO, Yasuhiro TAKESHITA 


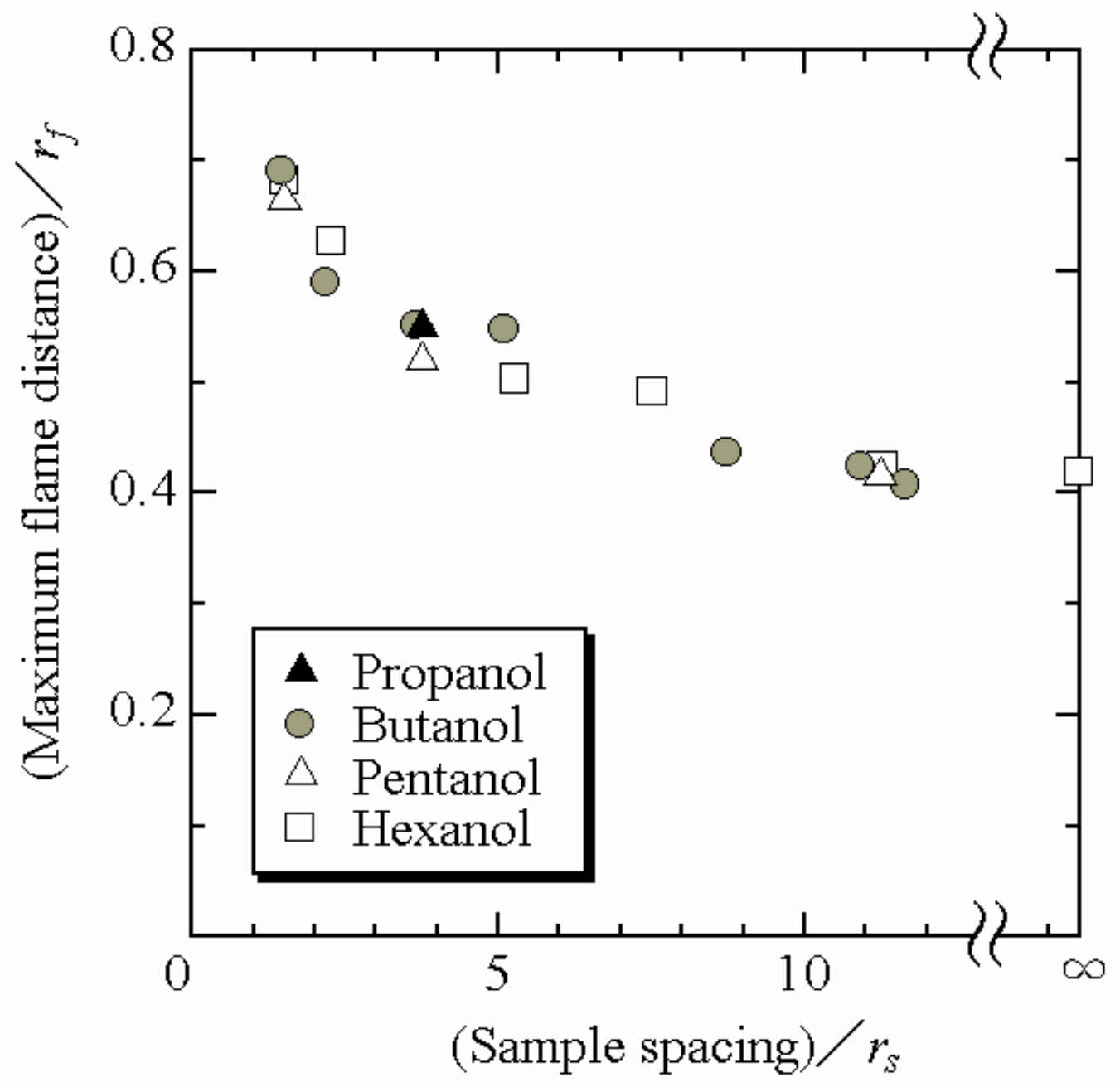

Fig. 10 (The maximum flame distance) $/ \mathrm{r}_{\mathrm{f}}$ as a function of (Sample space) $/ \mathrm{r}_{\mathrm{s}}$.

Harunori NAGATA, Sosuke NAKAMURA, Isao KUDO, Ken'ichi ITO, Yasuhiro TAKESHITA 


\section{Statement}

Reference: Interactive Combustion of Two-dimensionally Arranged Quasi-droplet Clusters under Microgravity

The content of the paper referenced above is unpublished material that is not being submitted for publication elsewhere. 
Prof. C. T. Bowman

Editor, "Combustion and Flame"

Department of Mechanical Engineering

Stanford University

Stanford, CA 94305-3032, U.S.A

Reference: Interactive Combustion of Two-dimensionally Arranged Quasi-droplet Clusters under Microgravity

Dear Prof. Bowman:

Enclosed are five copies of the manuscript of the paper referenced above which we are proposing to publish in "Combustion and Flame". The content of the paper is unpublished material that is not being submitted for publication elsewhere.

This paper is the revised one that has been originally reviewed on January 2000. The reference number was CF99-090. However, because more than a year has passed since then, I would like to send this paper as a new one.

Sincerely yours,

Harunori NAGATA

Associate professor

Enclosures: $\quad$ Five copies of the manuscript referenced above.

Five original statements.

Mail address: Department of Mechanical Science

Graduate School of engineering, Hokkaido University.

Sapporo 060-8628, JAPAN.

Tel: +81-11-706-7193 Fax: +81-11-706-7889

E-mail:nagata@eng.hokudai.ac.jp 